\title{
Rapid shifts in dominant taxa among microbial eukaryotes in estuarine ecosystems
}

\author{
Patrick Vigil ${ }^{1, *}$, Peter D. Countway ${ }^{2}$, Julie Rose ${ }^{3}$, Darcy J. Lonsdale ${ }^{4}$, \\ Christopher J. Gobler ${ }^{4}$, David A. Caron ${ }^{2}$ \\ ${ }^{1}$ Department of Microbiology and Immunology, University of Michigan Medical School, 1150 West Medical Center Drive, \\ 5641 Medical Science II, Ann Arbor, Michigan 48109-0620, USA \\ ${ }^{2}$ Department of Biological Sciences, University of Southern California, 3616 Trousdale Parkway, Los Angeles, \\ California 90089-0371, USA \\ ${ }^{3}$ Biology Department, MS \#32, Woods Hole Oceanographic Institution, Woods Hole, Massachusetts 02543, USA \\ ${ }^{4}$ School of Marine and Atmospheric Sciences, Stony Brook University, Stony Brook, New York 11794-5000, USA
}

\begin{abstract}
Studies in several estuarine ecosystems along the mid-Atlantic coast of the USA were carried out to examine short-term (every 1 to $3 \mathrm{wk}$ ) to long-term (seasonal-annual) shifts in the phylotypic composition of the planktonic microbial eukaryotic assemblage using terminal restriction fragment length polymorphism (T-RFLP) analyses. Fragment patterns revealed relatively rapid and striking shifts in the dominant phylotypes observed. Although the presence of some phylotypes was persistent or repetitive, dramatic changes in the overall composition of the microbial eukaryotic assemblage were observed for samples collected from a single environment at 1 to 2 wk intervals, samples collected on the same day from neighboring locales, and samples collected from different seasons. Bray-Curtis similarity values rarely indicated $\geq 70 \%$ similarity for any 2 sample pairs. Nonmetric multi-dimensional scaling and detrended correspondence analysis revealed a weak degree of relatedness among samples by location and season. Putative identifications of taxa comprising fragments of specific lengths were determined for 63 of the observed 162 fragment sizes from in silico restriction digests of partial $18 \mathrm{~S}$ gene sequences obtained from the samples. This approach identified a wide phylogenetic diversity of protistan taxa, despite the presence of significant 'brown tides' caused by the pelagophyte Aureococcus anophagefferens at some sampling times and locations. The regularity and rapidity with which the protistan assemblage restructured itself to yield unique combinations of dominant taxa indicates the existence of a highly dynamic and resilient microbial community that responded swiftly to changing environmental conditions in these estuaries.
\end{abstract}

KEY WORDS: Community dynamics $\cdot$ Aureococcus anophagefferens $\cdot$ Estuary $\cdot$ T-RFLP

\section{INTRODUCTION}

Estuaries of the mid-Atlantic states along the eastern coast of the USA comprise a complex system of highly dynamic and variable environments that have been heavily impacted historically by coastal land use, pollution, eutrophication and fisheries exploitation. In recent decades, these ecosystems have experienced a variety of harmful algal bloom events, most notably recurrent outbreaks of 'brown tides', noxious blooms caused by the minute $(\sim 2 \mu \mathrm{m})$ pelagophyte Aureococcus anophageffer- ens. While the specific cause of these blooms has been difficult to establish, a variety of factors have been implicated, including changes in the delivery of nutrients from groundwater, elevated organic nitrogen loading, reduced stocks of bivalve molluscs, and general ecosystem degradation (Cerrato et al. 2004, Gastrich et al. 2004, Wazniak \& Glibert 2004, Gobler et al. 2005). In turn, the development of brown tide events has disrupted pelagic and benthic food webs and, potentially, reduced overall ecosystem diversity (Tracey 1988, Buskey \& Hyatt 1995, Lonsdale et al. 1996, Bricelj \& Lonsdale 1997). 
Little information exists regarding the effect of harmful algal blooms on the overall diversity and taxonomic composition of pelagic food webs. General patterns of seasonal succession are well established for the larger phytoplankton species but, due to their general lack of a distinctive morphology, there is little understanding of the dynamics of small phytoplankton species and even less information on the composition and dynamics of most planktonic heterotrophic protists (Protozoa). It is unknown if the latter taxonomic groups are affected by the presence of noxious/toxic phytoplankton blooms, or if the rate of recovery of these communities is adversely affected by harmful algal blooms. These latter topics were the focus of the present study.

Few tools exist for examining the total diversity of natural communities of planktonic microbial eukaryotes (protists). Characteristics employed for species identification of protists vary greatly among the many taxa that collectively comprise the protistan plankton (Caron \& Schnetzer 2007), and traditional microscopical approaches cannot be used to identify the many, minute species that lack distinctive morphological characters. Consequently, a considerable amount of information exists regarding the species richness and abundance of specific groups of protists in numerous ecosystems, but little information exists regarding the diversity of any entire protistan assemblage.

The application of molecular biological approaches has begun to provide fruitful alternatives to traditional methods for characterizing microbial diversity. Two general genetic approaches have emerged for examining species diversity and composition of natural communities: cloning and sequencing of 'target' genes, and DNA fragment analysis. Sequencing of cloned genes obtained from environmental samples has been employed to provide insightful phylogenetic information on the microbial taxa present in nature, as well as the relative abundances of taxa within a community (Romari \& Vaulot 2004, Lovejoy et al. 2006, Countway et al. 2007), PCR biases and other artifacts notwithstanding (Berney et al. 2004). Such approaches are useful for estimating the total diversity of microbial communities because these assemblages have a high species richness and thus sequencing can resolve the presence of many of the 'rare' taxa if sufficient sequencing effort is expended (Sogin et al. 2006). However, studies of microbial diversity using DNA sequencing approaches are still relatively labor- and cost-intensive, and can therefore not readily be applied to large numbers of samples.

Alternatively, several approaches using DNA fragment analysis to assess the number and relative abundances of microbial taxa have also been developed for natural samples. Approaches commonly applied to prokaryote and eukaryote assemblages have included denaturing gradient gel electrophoresis (DGGE), terminal restriction fragment polymorphisms (T-RFLP), automated ribosomal intergenic spacer analysis (ARISA) and amplified ribosomal DNA restriction analysis (ARDRA) (Casamayor et al. 2002, Gast et al. 2004). These methods have been employed to provide an estimate of community structure in a sample (Van Hannen et al. 1998, Díez et al. 2001, Díez et al. 2004, Gast et al. 2004, Zeidner \& Béjà 2004, Baldwin et al. 2005, Countway et al. 2005). Fragment analysis can also provide some degree of taxonomic information when combined with ancillary data (e.g. DNA sequence information) that relate specific fragment lengths to known sequenced organisms (Saari et al. 2007). While the number of taxa (i.e. unique bands) that can be detected using fragment analyses is limited when compared to the resolution provided by cloning and sequencing, the relative ease and low cost of fragment analysis allow its application to a much larger number of samples. Thus, fragment analyses can be particularly useful for comparative studies of the species composition of natural microbial assemblages and for detecting shifts in the relative abundance of the most abundant taxa within a community.

For the present study, 66 samples were collected from 6 estuarine environments along the eastern US coast off Long Island, New York and Maryland during 2003 and 2004, which included samples taken from Maryland waters during a major brown tide. T-RFLP was employed to examine shifts in the composition of the microbial eukaryotic community at each site at 1 to 3 wk intervals during the summer of both years.

\section{MATERIALS AND METHODS}

Sample collection. Plankton samples were collected from 6 study sites, which have been historically prone to brown tide blooms (Deonarine et al. 2006), during the spring and summer (May to August) of 2003 and 2004 (Fig. 1). Briefly, the estuarine environments included 4 locations on Long Island, New York: Quantuck Bay $\left(\mathrm{QB}_{;} 40.81^{\circ} \mathrm{N}, 72.62^{\circ} \mathrm{W}\right)$, Bay Shore Cove $\left(\mathrm{BSC}_{;} 40.70^{\circ} \mathrm{N}, 73.23^{\circ} \mathrm{W}\right)$, Patchogue Bay $\left(\mathrm{PB}_{;} 40.73^{\circ}\right.$ $\left.\mathrm{N}, 73.02^{\circ} \mathrm{W}\right)$ and western Shinnecock Bay $\left(\mathrm{SB}_{;}\right.$40.83 $\left.\mathrm{N}, 72.57^{\circ} \mathrm{W}\right)$. Two locations were sampled in Chincoteague Bay, Maryland: Public Landing (PL; $38.15^{\circ} \mathrm{N}$, $75.29^{\circ} \mathrm{W}$ ) and Greenbackville (GBV; $38.02^{\circ} \mathrm{N}, 75.36^{\circ}$ $\mathrm{W})$. Seawater was collected from just below the surface in replicate 201 polycarbonate carboys. Samples were kept cool and dark during transport to the laboratory, where they were processed. Physical and chemical measurements $(T$, salinity, chlorophyll, dissolved inorganic nitrogen, disolved organic carbon, phosphate, 
particulate organic nitrogen, particulate organic carbon, and silicate levels) were collected according to methods described in Deonarine et al. (2006) and Gobler \& Sañudo-Wilhelmy (2001). Replicate samples were prefiltered through $80 \mu \mathrm{m}$ Nitex mesh (to remove most metazoa) before filtering onto GF/F Gelman glass fiber filters. Filters were placed in cryovials and $0.5 \mathrm{ml}$ of lysis buffer were added. Samples were frozen in liquid nitrogen and stored at $-80^{\circ} \mathrm{C}$ until processing for DNA extraction. A total of 66 samples was analyzed (see Table 1).

DNA extraction. DNA extractions, PCR amplifications and T-RFLP analyses followed those described in Countway et al. (2005) with slight modifications. At the time of DNA extraction, $200 \mu \mathrm{l}$ of $0.5 \mathrm{~mm}$ diameter zirconia/silica beads were added to each cryovial and the mixture was incubated at $70^{\circ} \mathrm{C}$ for $5 \mathrm{~min}$. Each cryovial was vortexed at high speed for $30 \mathrm{~s}$ to disrupt cell walls and membranes. Each sample was processed with 3 rounds of heating and vortexing to ensure complete cell lysis. The liquid phase was then separated from filter debris and beads by pushing the mixture through the tip of a $5 \mathrm{ml}$ syringe. The lysis solution was adjusted to a final concentration of $0.7 \mathrm{M} \mathrm{NaCl}$ and $1 \%$ hexadecyltrimethyl-ammonium bromide (CTAB, Sigma-Aldrich) and incubated at $70^{\circ} \mathrm{C}$ for $10 \mathrm{~min}$.

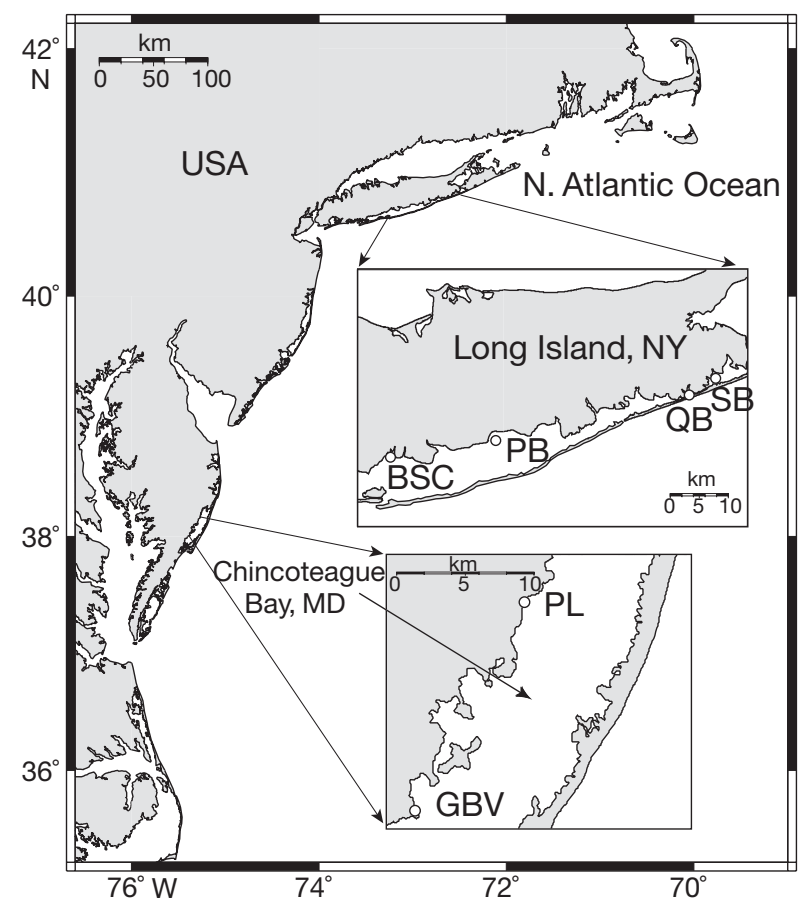

Fig. 1. Atlantic coast of the USA. Sampling locations in estuaries along the coast of Long Island, New York and in Chincoteague Bay, Maryland, are shown enlarged in the inserts (BSC: Bay Shore Cove, PB: Patchogue Bay, QB: Quantuck Bay, SB: Shinnecock Bay, PL: Public Landing, GBV: Greenbriarville)
Extraction was performed with an equal volume of phenol-chloroform-isoamyl alcohol (25:24:1), and residual phenol was removed with an equal volume of chloroform-isoamyl alcohol (24:1). DNA was precipitated with 1 volume $95 \%$ ethanol and 0.1 volume of ammonium acetate, resuspended in TE buffer $(10 \mathrm{mM}$ Tris, $1 \mathrm{mM}$ EDTA, pH 7.5), and stored at $-20^{\circ} \mathrm{C}$ until analyzed.

PCR amplification of DNA fragments. Fragments of the small subunit ribosomal RNA gene (18S) of approximately $600 \mathrm{bp}$ were amplified from the extracted DNA using the D4 (Beckman-Coulter) fluorescently labeled forward primer D4-Euk-A (5'-D4-AAC CTG GTT GAT CCT GCC AGT-3') and the unlabeled reverse primer Euk-570R (5'-GCT ATT GGA GCT GGA ATT AC-3'). Each $50 \mu$ reaction contained a final concentration of $1 \times$ PCR buffer solution (Promega), $0.5 \mu \mathrm{M}$ of each primer, $2.5 \mathrm{mM} \mathrm{MgCl}_{2}$ (Promega), $0.3 \mu \mathrm{gl}^{-1}$ bovine serum albumin (Sigma-Aldrich), and 2.5 units Taq polymerase (Promega), to which $3 \mu \mathrm{l}$ of a 1:10 dilution of the extracted DNA was added. All samples were amplified using the following protocol: initial denaturation at $95^{\circ} \mathrm{C}$ for $2 \mathrm{~min}, 35$ cylces of amplification $\left(95^{\circ} \mathrm{C}\right.$ for $30 \mathrm{~s}, 60^{\circ} \mathrm{C}$ for $30 \mathrm{~s}, 72^{\circ} \mathrm{C}$ for $60 \mathrm{~s}$ ), and a final extension at $72^{\circ} \mathrm{C}$ for $5 \mathrm{~min}$. Three replicate reactions were run at the same time for each sample and the resulting products were combined before processing for T-RFLP analysis.

T-RFLP analysis. PCR products were purified and concentrated with the UltraClean PCR clean-up kit (Mo-Bio Laboratories) and then incubated for $60 \mathrm{~min}$ at $30^{\circ} \mathrm{C}$ with $10 \mathrm{U}$ mung bean nuclease (New England Biolabs) to remove single stranded PCR artifacts (Egert $\&$ Friedrich 2003). Mung bean digested products were purified with a second UltraClean PCR clean-up kit (Mo-Bio Laboratories). The PCR products were run on a $1.2 \%$ SeaKem agarose (Cambrex) gel in $1 \times$ TBE buffer (Bio-Rad) to remove nonspecific products. Bands of appropriate size (approximately $600 \mathrm{bp}$ ) were excised from the gels and gel bands were purified with the UltraClean 15 DNA purification kit (Mo-Bio Laboratories). Purified DNA was separated into two $10 \mu \mathrm{l}$ aliquots, each of which was used in a separate restriction enzyme reaction: $10 \mathrm{U}$ of the restriction enzyme Mnl I was used in one and $10 \mathrm{U}$ of Hha I in the other (New England Biolabs). All restriction enzyme reactions were incubated at $37^{\circ} \mathrm{C}$ overnight (about 14 to $16 \mathrm{~h})$. Mnl I generally yielded higher numbers of fragments than Hha I; therefore, only the results of the Mnl I digests are presented.

After incubation, restriction fragments were precipitated in the presence of $20 \mu \mathrm{g}$ of glycogen (Roche) using $2 \mu \mathrm{l}$ of $3 \mathrm{M}$ sodium acetate (Sigma-Aldrich) and $50 \mu$ l of ice-cold $95 \%$ ethanol. Samples were mixed and then centrifuged at $4^{\circ} \mathrm{C}$ and $6000 \times g$ for $15 \mathrm{~min}$. 
Table 1. Sample locations and pertinent physical and chemical parameters at the time of each sampling in 6 estuaries. Chlorophyll (Chl) units are $\mu g \mathrm{l}^{-1}$. Units for dissolved inorganic nitrogen (DIN: nitrate + nitrite + ammonium), phosphate, particulate organic nitrogen (PON), and particulate organic carbon (POC) concentrations are in $\mu \mathrm{M}$. The number of fragments (above threshold) detected in each sample are listed, along with diversity estimates based on the T-RFLP data and utilizing the Shannon $\left(H^{\prime}\right)$ and Simpson (1/1) diversity indices (Brower et al. 1998). See Fig. 1 for definitions of location abbreviations. Dates are given as dd.mm.yy. N/A: not available. T, salinity, DIN, phosphate, and PON data for QB and PL sites previously published (Deonarine et al. 2006). Dissolved organic carbon (DOC) and silicate levels not shown

\begin{tabular}{|c|c|c|c|c|c|c|c|c|c|c|}
\hline $\begin{array}{l}\text { Collection } \\
\text { date }\end{array}$ & $\begin{array}{l}\mathrm{T} \\
\left({ }^{\circ} \mathrm{C}\right)\end{array}$ & Salinity & Chl & DIN & Phosphate & PON & POC & $\begin{array}{l}\text { \# of fragments } \\
\text { above threshold }\end{array}$ & $H^{\prime}$ & $1 / 1$ \\
\hline \multicolumn{11}{|l|}{ QB } \\
\hline 03.05 .2003 & 14.98 & 27.35 & 4.34 & 0.84 & 0.51 & 6.46 & 77.35 & 23 & 1.98 & 3.29 \\
\hline 19.05 .2003 & 14.77 & 28.05 & 6.35 & 8.53 & 0.40 & 10.19 & 83.41 & 28 & 2.84 & 11.17 \\
\hline 03.06 .2003 & 17.83 & 23.64 & 17.70 & 0.88 & 0.25 & 13.44 & 101.13 & 19 & 2.07 & 4.36 \\
\hline 09.06 .2003 & 18.05 & 21.38 & 21.03 & 1.47 & 0.44 & 12.36 & 143.14 & 12 & 1.04 & 1.70 \\
\hline 16.06 .2003 & 19.38 & 25.23 & 12.99 & 1.07 & 0.36 & 8.36 & 130.88 & 34 & 2.73 & 7.33 \\
\hline 25.06 .2003 & 23.54 & 23.42 & 12.63 & 0.92 & 0.27 & N/A & N/A & 10 & 1.32 & 2.28 \\
\hline 30.06 .2003 & 25.36 & 24.74 & 11.79 & 1.32 & 0.47 & N/A & N/A & 15 & 1.75 & 3.56 \\
\hline 21.07 .2003 & 25.66 & 25.39 & 18.79 & 5.03 & 0.78 & 13.40 & 126.66 & 33 & 3.05 & 15.17 \\
\hline 06.08 .2003 & 26.74 & 26.78 & 26.37 & 0.39 & 0.19 & 16.80 & 155.61 & 27 & 2.41 & 6.13 \\
\hline 01.05 .2004 & 15.04 & 25.00 & 2.77 & 4.50 & 0.30 & 9.36 & 67.08 & 22 & 2.15 & 4.34 \\
\hline 15.05 .2004 & 18.70 & 23.26 & 3.84 & 4.65 & 0.50 & 13.27 & 133.61 & 19 & 1.88 & 3.43 \\
\hline 03.06 .2004 & 20.90 & 26.34 & 8.25 & 3.53 & 0.20 & 12.74 & 136.94 & 21 & 1.98 & 4.06 \\
\hline 08.06 .2004 & 19.97 & 27.51 & 11.71 & 4.22 & 0.45 & 12.36 & 100.73 & 28 & 2.79 & 11.17 \\
\hline 14.06 .2004 & 20.42 & 28.20 & 12.37 & 3.43 & 1.08 & N/A & N/A & 31 & 2.80 & 10.07 \\
\hline 06.07 .2004 & 25.37 & 28.22 & 11.30 & 9.41 & 0.54 & 14.67 & 127.51 & 31 & 2.65 & 7.37 \\
\hline 19.07 .2004 & 24.42 & 27.75 & 25.97 & 0.62 & 0.88 & 18.22 & 153.21 & 36 & 3.09 & 14.72 \\
\hline \multicolumn{11}{|l|}{ SB } \\
\hline 03.05 .2003 & 15.85 & 26.94 & 4.00 & 0.80 & 0.28 & 11.41 & 97.94 & 16 & 1.63 & 2.81 \\
\hline 19.05 .2003 & 13.88 & 30.00 & 6.19 & 0.79 & 0.45 & N/A & N/A & 29 & 2.93 & 13.34 \\
\hline 03.06 .2003 & 16.76 & 27.86 & 4.46 & 2.57 & 0.76 & N/A & N/A & 36 & 3.10 & 13.24 \\
\hline 16.06 .2003 & 18.09 & 28.92 & 11.97 & 0.82 & 0.58 & N/A & N/A & 32 & 2.84 & 9.42 \\
\hline 30.06 .2003 & 22.04 & 29.03 & 10.06 & 0.82 & 0.76 & 7.76 & 110.87 & 16 & 1.31 & 1.96 \\
\hline 21.07 .2003 & 23.20 & 29.01 & 13.09 & 0.86 & 1.08 & 12.97 & 97.59 & 14 & 1.37 & 2.14 \\
\hline 06.08 .2003 & 23.98 & 29.69 & 14.37 & 0.90 & 0.95 & 11.71 & 111.34 & 27 & 2.60 & 8.18 \\
\hline 01.05 .2004 & 13.39 & 27.55 & 2.61 & 1.56 & 0.52 & N/A & N/A & 27 & 2.42 & 5.57 \\
\hline 15.05 .2004 & 17.33 & 26.55 & 1.90 & 5.53 & 0.65 & 3.16 & 77.09 & 26 & 2.09 & 3.45 \\
\hline 03.06 .2004 & 19.50 & 28.63 & 5.22 & 3.93 & 0.70 & 8.23 & 72.43 & 17 & 1.86 & 3.97 \\
\hline 14.06 .2004 & 21.21 & 27.67 & 10.01 & 0.54 & 0.67 & 17.65 & 187.38 & 16 & 1.46 & 2.27 \\
\hline 06.07 .2004 & 22.80 & 30.64 & 4.79 & 9.56 & 1.50 & 21.09 & 194.82 & 34 & 3.09 & 16.15 \\
\hline 19.07 .2004 & 24.06 & 28.65 & 9.77 & 0.90 & 0.50 & 11.70 & 100.90 & 21 & 2.56 & 10.18 \\
\hline \multicolumn{11}{|l|}{ BSC } \\
\hline 03.05 .2003 & 14.42 & 25.31 & 1.29 & 0.61 & 0.27 & 3.61 & 45.88 & 33 & 2.71 & 6.61 \\
\hline 21.05 .2003 & 15.53 & 26.33 & 2.55 & 0.40 & 0.37 & 3.38 & 53.19 & 31 & 2.80 & 10.71 \\
\hline 05.06 .2003 & 16.47 & 22.49 & 4.39 & 6.28 & 0.38 & 5.02 & 58.42 & 34 & 3.00 & 12.15 \\
\hline 10.06 .2003 & 18.77 & 22.43 & 4.40 & 3.56 & 0.18 & 6.94 & 72.02 & 29 & 2.58 & 6.41 \\
\hline 18.06 .2003 & 20.10 & 22.41 & 5.77 & 0.85 & 0.31 & 37.16 & 387.02 & 25 & 2.55 & 8.20 \\
\hline 25.06 .2003 & 23.20 & 22.41 & 5.28 & 1.35 & 0.57 & 23.22 & 245.26 & 19 & 2.25 & 6.19 \\
\hline 01.07 .2003 & 25.45 & 23.13 & 3.88 & 3.30 & 0.36 & 21.39 & 213.53 & 26 & 2.68 & 9.74 \\
\hline 25.07 .2003 & 24.32 & 24.15 & 13.34 & 4.70 & 0.76 & 19.47 & 298.90 & 17 & 1.79 & 3.03 \\
\hline 06.08 .2003 & 25.39 & 26.23 & 10.67 & 0.85 & 0.71 & 26.88 & 305.30 & 24 & 2.68 & 10.85 \\
\hline 01.05 .2004 & 14.64 & 24.62 & 13.09 & 2.02 & 0.12 & 15.52 & 129.36 & 25 & 2.39 & 6.77 \\
\hline 15.05 .2004 & 18.19 & 25.28 & 4.93 & 1.05 & 0.54 & 16.75 & 180.64 & 33 & 3.16 & 18.07 \\
\hline 01.06 .2004 & 18.75 & 24.86 & 7.25 & 4.69 & 0.95 & 16.73 & 115.99 & 34 & 3.02 & 13.59 \\
\hline 10.06 .2004 & 22.82 & 23.54 & 9.07 & 5.65 & 0.42 & 13.85 & 113.01 & 34 & 3.09 & 14.36 \\
\hline 23.06 .2004 & 25.70 & 25.55 & 5.67 & 3.46 & 0.51 & 18.38 & 134.52 & 32 & 2.95 & 12.20 \\
\hline 22.07 .2004 & 26.35 & 28.08 & 3.66 & 0.26 & 1.07 & 21.32 & 185.92 & 29 & 2.72 & 10.31 \\
\hline \multicolumn{11}{|l|}{ PB } \\
\hline 03.05 .2003 & 14.58 & 24.76 & 2.47 & 3.57 & 0.19 & 4.91 & 72.72 & 31 & 2.89 & 11.63 \\
\hline 21.05 .2003 & 15.79 & 25.37 & 6.10 & 0.59 & 0.29 & 8.24 & 111.37 & 27 & 2.43 & 6.51 \\
\hline 05.06 .2003 & 16.32 & 21.87 & 11.93 & 8.15 & 0.53 & 10.62 & 100.92 & 28 & 2.51 & 6.09 \\
\hline 18.06 .2003 & 20.09 & 20.28 & 8.43 & 6.12 & 0.26 & N/A & N/A & 26 & 2.76 & 11.77 \\
\hline 01.07 .2003 & 25.96 & 19.96 & 12.14 & 0.42 & 0.43 & 8.95 & 112.58 & 28 & 2.70 & 9.87 \\
\hline 25.07 .2003 & 24.65 & 20.68 & 17.53 & 7.06 & 0.50 & 37.63 & 339.85 & 18 & 2.34 & 7.89 \\
\hline 06.08 .2003 & 25.55 & 21.46 & 21.16 & 0.38 & 0.51 & 39.39 & 385.92 & 23 & 2.41 & 5.84 \\
\hline 01.05 .2004 & 14.44 & 23.44 & 7.94 & 5.72 & 0.23 & 14.36 & 127.23 & 20 & 1.68 & 2.53 \\
\hline
\end{tabular}


Table 1 (continued)

\begin{tabular}{|c|c|c|c|c|c|c|c|c|c|c|}
\hline $\begin{array}{l}\text { Collection } \\
\text { date }\end{array}$ & $\begin{array}{l}\mathrm{T} \\
\left({ }^{\circ} \mathrm{C}\right)\end{array}$ & Salinity & $\mathrm{Chl}$ & DIN & Phosphate & PON & POC & $\begin{array}{l}\text { \# of fragments } \\
\text { above threshold }\end{array}$ & $H^{\prime}$ & $1 / 1$ \\
\hline \multicolumn{11}{|c|}{ PB (continued) } \\
\hline 15.05 .2004 & 18.83 & 22.71 & 7.65 & 7.17 & 0.60 & 17.21 & 164.32 & 30 & 2.80 & 10.27 \\
\hline 01.06 .2004 & 19.05 & 22.79 & 7.68 & 4.94 & 0.18 & 15.49 & 140.47 & 28 & 2.84 & 12.40 \\
\hline 23.06 .2004 & 22.77 & 22.89 & 4.00 & 8.48 & 1.86 & 18.94 & 125.52 & 34 & 3.06 & 14.70 \\
\hline 22.07 .2004 & 26.44 & 24.13 & 16.70 & 2.63 & 1.22 & 41.76 & 323.32 & 15 & 1.98 & 4.30 \\
\hline \multicolumn{11}{|l|}{ PL } \\
\hline 17.06 .2004 & 24.78 & 28.09 & 25.54 & 0.96 & 1.41 & N/A & N/A & 18 & 1.59 & 2.39 \\
\hline 28.06 .2004 & 24.38 & 30.40 & 16.09 & 3.24 & 1.15 & N/A & N/A & 28 & 2.75 & 9.89 \\
\hline 13.07 .2004 & 26.30 & 31.17 & 22.34 & 1.09 & 1.08 & N/A & N/A & 20 & 2.38 & 7.07 \\
\hline 24.07 .2004 & N/A & N/A & N/A & N/A & N/A & N/A & N/A & 28 & 2.83 & 12.46 \\
\hline 10.08 .2004 & 24.03 & 27.17 & 22.39 & 0.69 & 1.54 & N/A & N/A & 22 & 2.41 & 5.68 \\
\hline \multicolumn{11}{|l|}{ GBV } \\
\hline 17.06 .2004 & 27.30 & 32.35 & 23.48 & 2.37 & 1.62 & N/A & N/A & 20 & 2.36 & 6.90 \\
\hline 28.06 .2004 & 24.63 & 32.15 & 17.48 & 0.56 & 1.33 & N/A & N/A & 25 & 2.56 & 6.94 \\
\hline 13.07 .2004 & 27.30 & 32.10 & 11.27 & 5.32 & 2.13 & N/A & N/A & 27 & 2.55 & 8.25 \\
\hline 24.07 .2004 & N/A & N/A & N/A & N/A & N/A & N/A & N/A & 29 & 2.63 & 8.57 \\
\hline 10.08 .2004 & 25.10 & 27.29 & 14.71 & 6.02 & 2.15 & N/A & N/A & 24 & 2.40 & 7.47 \\
\hline
\end{tabular}

The ethanol was decanted from the pellets and the pellets washed with $100 \mu \mathrm{l}$ of $70 \%$ ethanol and centrifuged at $4^{\circ} \mathrm{C}$ and $6000 \times g$ for $5 \mathrm{~min}$. The wash procedure was repeated and, after decanting, the pellets were air dried for $20 \mathrm{~min}$. Pelleted PCR fragments were resuspended in $40 \mu \mathrm{l}$ of deionized formamide (Beckman Coulter). Of this resuspension, $5 \mu$ l were diluted with $34.5 \mu$ of additional deionized formamide and mixed with $0.5 \mu$ l of DNA Size Standard Kit-600 (Beckman Coulter) and run on a CEQ8000 capillary gelelectrophoresis DNA sequencer following Countway et al. (2005).

The reproducibility of the T-RFLP patterns obtained in this study was examined by comparing the T-RFLP patterns generated for 2 samples (QB: 9 June 2003; and PB: 1 June 2004) that were subsampled and the subsamples processed independently for T-RFLP analysis. The subsamples were analyzed in triplicate.

Data analysis. Raw data were analyzed using the Fragment Analysis module of the CEQ 8000 software package (Beckman Coulter). The fragments were separated into $1 \mathrm{bp}$-wide bins, based on comparison to the known sizes of DNA Size Standard Kit-600 that was run with each sample, and the results were exported into a spreadsheet. The total peak area of each sample was normalized to the same relative scale to allow for comparisons of relative peak abundance across samples (Kaplan \& Kitts 2004). To visualize the results from all samples simultaneously, a heatmap was generated using the program Heatmap Builder (King et al. 2005).

Cloning and sequencing of $18 \mathrm{~S}$ genes. The purpose of the cloning and sequencing effort was to provide putative identifications for the DNA fragments generated by the T-RFLP analysis. Extracted DNA from 8 of the 66 samples was used for the amplification and cloning of full-length, small subunit ribosomal RNA genes (18S). Five samples from Quantuck Bay (QB: 3 May and 6 August 2003, and 1 May, 3 June and 19 July 2004) and 3 samples from Public Landing (PL: 17 June, 18 July and 10 August 2004) were used in the cloning and sequencing work. The 5' ends of the genes from these samples were sequenced (i.e. the fragment labeled as part of the T-RFLP analysis) and then analyzed for the expected fragment sizes generated by these sequences in the T-RFLP analysis (see next section). The amplification, cloning and sequencing protocols have previously been described in detail (Countway et al. 2005).

Briefly, genes were amplified using universal eukaryote primers; Euk-A (5'-AAC CTG GTT GAT CCT GCC AGT-3') and Euk-B (5'-GAT CCT TCT GCA GGT TCA CCT AC-3') to generate products for TA cloning and subsequent sequencing. The PCR thermal protocol was 1 cycle of $95^{\circ} \mathrm{C}$ for 2 min, 35 cycles of $95^{\circ} \mathrm{C}$ for $30 \mathrm{~s}, 50^{\circ} \mathrm{C}$ for $30 \mathrm{~s}$ and $72^{\circ} \mathrm{C}$ for $2.5 \mathrm{~min}$, with a final extension at $72^{\circ} \mathrm{C}$ for $7 \mathrm{~min}$. DNA sequencing was carried out on a Beckman-Coulter CEQ8000 automated DNA sequencer using primers located on the plasmid in order to obtain at least $600 \mathrm{bp}$ of the $5^{\prime}$ end of the $18 \mathrm{~S}$ genes (i.e. the fragment labeled and analyzed as part of the T-RFLP analysis).

Putative identifications of T-RFLP peaks. In silico restriction enzyme digests were performed on the DNA sequences obtained to assign putative identities to as many T-RFLP peaks as possible. Enzyme cut sites were identified by searching for the first site from the $5^{\prime}$ end of the $18 \mathrm{~S}$ genes to putatively identify fragment lengths appearing in the T-RFLP patterns. In practice, 
fragment lengths determined from T-RFLP patterns are affected by parameters other than bp length (e.g. purine content). However, we have obtained good agreement between these fragment lengths predicted from sequence information and T-RFLP fragment lengths using single species to groundtruth the approach (Caron et al. 2004). Sequences obtained from the clone libraries generated from these samples have been submitted to GenBank (www.ncbi.nlm.nih.gov/ Genbank/, accession numbers FJ221389 to FJ222198). Specific identities of the T-RFLP peaks were based on the nearest BLAST match (http://blast.ncbi.nlm.nih. gov/Blast.cgi, Altschul et al. 1997) of the 18S rRNA gene sequences that exhibited a theoretical restriction fragment matching the exact size of a T-RFLP peak on one of our chromatograms (Table 2).

Multivariate statistical analysis. The community fingerprints generated from relative abundance of $\mathrm{T}$ RFLP fragment lengths within samples were compared among all locations and sampling dates using several multivariate statistical tools. Relationships among samples were first visualized using 3 'mapping' techniques of community similarity. First, detrended correspondence analysis (DCA) was performed using a modified form of the DECORANA software (available at http:// cc.oulu.fi/ jarioksa/softhelp/ceprog.html), which corrects a software error in the original program (Oksanen \& Minchin 1997). A Bray-Curtis coefficient was used to generate the similarity matrix using a square root transformation to slightly upweight the contribution of rarer fragment lengths. A hierarchical agglomerative clustering method with group-average linkage was used to generate a dendrogram illustrating relationships among the samples. Finally, non-metric multidimensional scaling (MDS) was used to map sample relationships in 2- and 3-dimensional space. Information about sample location and time were then overlaid on the MDS plot to explore potential structuring within the data. DCA and MDS were conducted on both normalized and square root-transformed data. The transformation, similarity matrix, cluster analysis and MDS plots were all generated using the multivariate statistical software program PRIMER version 6.1.5 (PRIMER-E, Plymouth UK). PRIMER was selected for our analyses since it was specifically designed for biological assemblage datasets and employs a series of rank- and permutation-type analyses with few assumptions about the assemblage and environmental data.

A series of hypotheses were also tested using the PRIMER software program. The ANOSIM test was used to determine the level of statistical significance of sample groupings based on sample location (comparing individual sample sites, or northern and southern regions), year (2003 vs. 2004), and the month during which samples were taken. The ANOSIM test is the multivariate analog to the commonly employed univariate ANOVA test, but is adapted for biological assemblages and based on a non-parametric permutation method. The BV-STEP procedure in PRIMER was used to identify the subset of fragment lengths responsible for driving the patterns observed in the DCA, cluster and MDS analyses. This procedure worked in a stepwise manner using increasingly larger, randomly generated subsets of the total species/fragment lengths list to find a subset whose species matrix had a $>0.95$ correlation to the original species matrix. Alternate subsets were then generated by removing the species identified in the significant subset and repeatedly performing the BV-STEP procedure until a subset whose species matrix had a $>0.95$ correlation to the original species matrix could no longer be identified.

Finally, the relationship between environmental variables and community fingerprint patterns was explored using the BIO-ENV test within the PRIMER software. The BIO-ENV test could only be run with the samples collected in New York due to the limited environmental data available for the Maryland samples. This procedure operates by matching similarity matrices based on species assemblage data with an increasing number and combination of environmental variables from the same samples to find the best correlation between the 2 data sets. The species/fragment length similarity matrix was generated as described above. The few missing data points in the New York environmental data set were approximated using the expectation-maximization algorithm provided in the PRIMER software. The matrix for environmental variables was generated by normalizing measurements followed by the calculation of Euclidean distance measures of sample dissimilarity. The 2 matrices were then compared using a rank correlation coefficient.

\section{RESULTS}

Temperature, phytoplankton pigment concentrations, dissolved nutrient concentrations, particulate organic carbon (POC) and particulate organic nitrogen (PON) concentrations largely overlapped among the different estuaries (Table 1). This result was not surprising given the seasonal range over which samples were collected and their similar regional locales. Temperatures in the estuaries during the study ranged from approximately 14 to $27^{\circ} \mathrm{C}$. Maximum chlorophyll a ( $\mathrm{chl} \mathrm{a)} \mathrm{concentrations} \mathrm{were} 26 \mu \mathrm{g} \mathrm{l^{-1 }}$, and the highest concentrations were generally attained during mid- to late summer. Similar trends were observed for PON and POC. Dissolved inorganic nitrogen (DIN: nitrate + nitrite + ammonium) and phosphate concentrations 


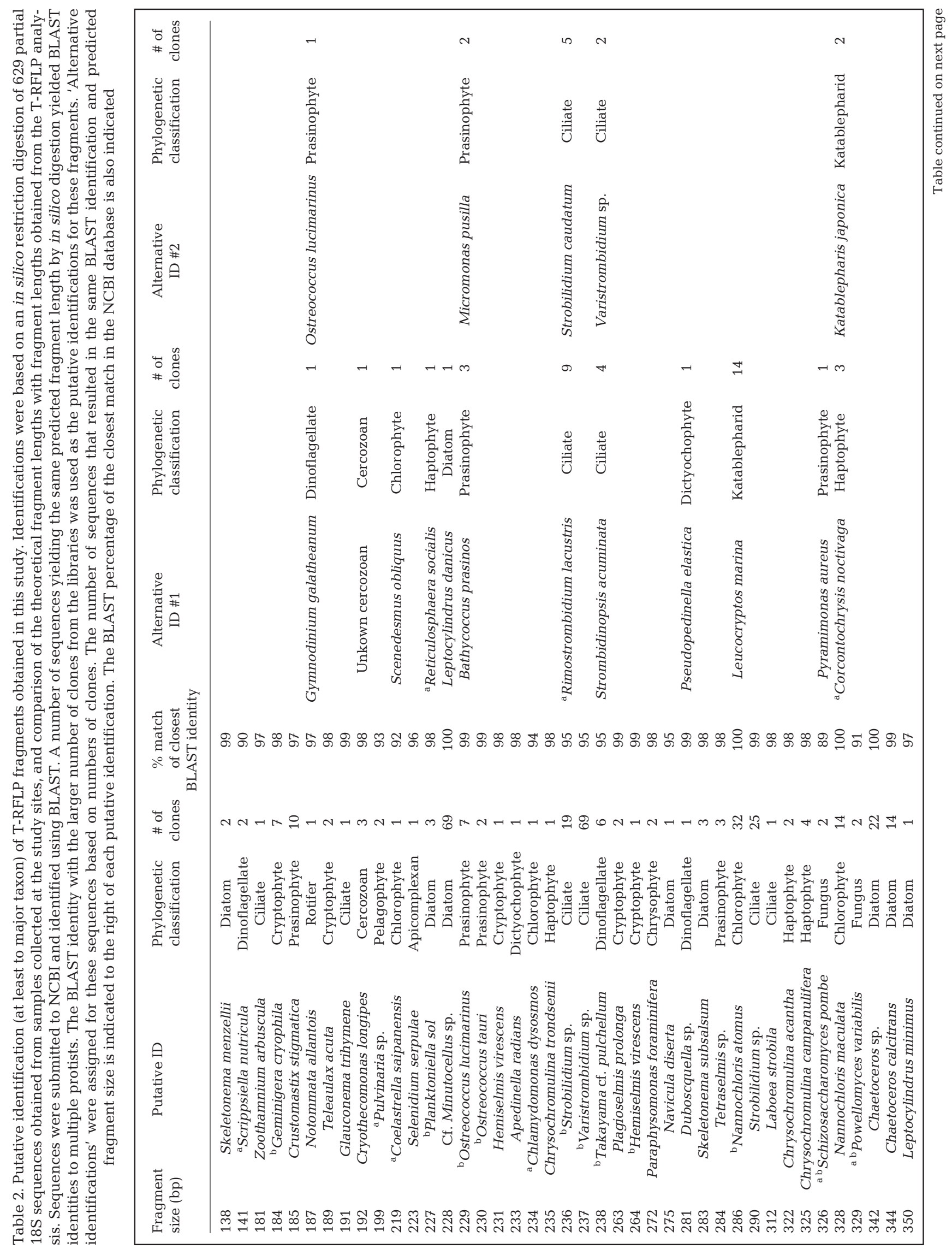




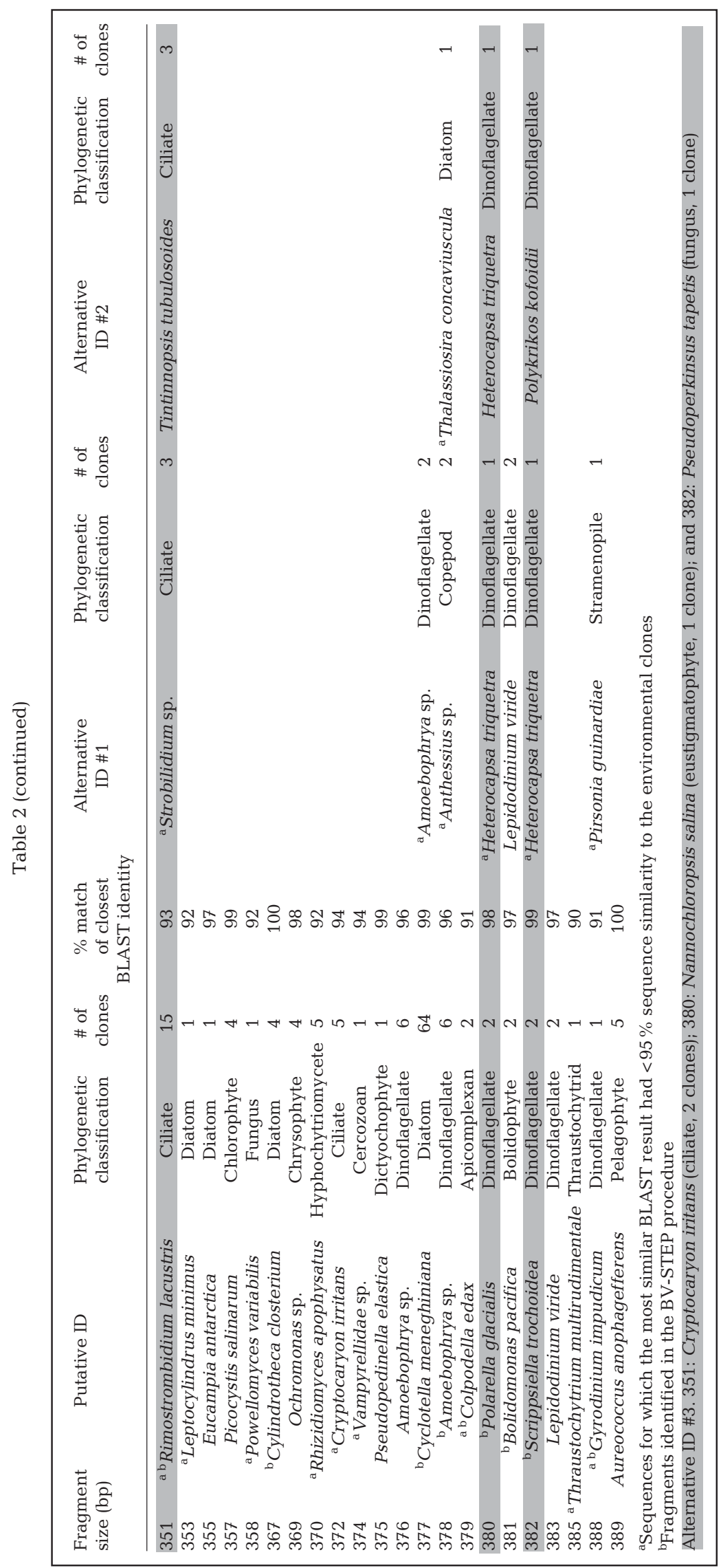

were representative of moderately eutrophic estuarine ecosystems (overall ranges ca. 0.4 to $9.6 \mu \mathrm{M}$ for DIN and ca. 0.2 to $2.1 \mu \mathrm{M}$ for phosphate).

An average of 25 fragments per sample were obtained over the entire data set, with a maximum of 36 and a minimum of 10 fragments per sample (Table 1). A total of 162 unique fragment sizes were obtained across all 66 samples. Samples collected at the southern sites during an intense brown tide on June 17 and 28 (Deonarine et al. 2006) did not have markedly lower diversity indices during these events (Table 1).

T-RFLP patterns were highly reproducible under the conditions employed in this study. Reproducibility of the T-RFLP patterns was examined by comparing the patterns derived from 2 samples in this study (QB: 9 June 2003 and PB: 1 June 2004) for which amplifications, digestions and T-RFLP analysis were conducted independently in triplicate (data not shown). Comparison of the fragment patterns yielded standard deviations of 0.02 to $3.8 \%$ of the total peak area for each fragment size across all fragments in the analysis (an average standard deviation of $0.58 \%$ for all fragment sizes) with 2 exceptions. Two fragments in one of the replicates were assigned a fragment size $1 \mathrm{bp}$ larger than its assignment in the other 2 replicates. Inclusion of these fragments in the analysis increased the average standard deviation to $1.33 \%$ total peak area.

A comparison of samples collected at approximately 1 to $2 \mathrm{wk}$ intervals within a single estuary indicated rapid temporal changes in the dominant phylotypes (i.e. phylotypes defined as DNA fragments of unique length) present within an ecosystem over short temporal and spatial scales, and substantial differences in community composition across ecosystems at any given time. Data from each fragment pattern were normalized in order to express each fragment as a percentage of the total peak area, and patterns across all ecosystems were assembled into a single heatmap to allow visual comparisons among all of the samples (Fig. 2). A number of fragment sizes were observed to reoccur in successive samples from each sample location (e.g. 237, 327, $329 \mathrm{bp}$ ), and some phylotypes were consistently observed in all or most 
ecosystems (e.g. 378, 381 bp); however, in general this comparison revealed numerous shifts in the dominant phylotypes at all sampling locations and within each ecosystem on time spans of 1 to $2 \mathrm{wk}$.

Three raw chromatograms from the 66 T-RFLP patterns obtained in this study illustrate the rapid changes in community structure observed in the fragment analyses of samples collected sequentially from a single site (Fig. 3). These 3 samples were collected from Shinnecock Bay at approximately $2 \mathrm{wk}$ intervals. The 13 dominant phylotypes (i.e. distinct fragment sizes indicated on the chromatograms) were all different among the 3 samples.

Rapid shifts in the dominant phylotypes of each T-RFLP pattern observed at all sampling locations were evident in graphs depicting changes for each given locale (Figs. 4 to 6). For example, the dominant phylotype at $\mathrm{PL}$ and GBV in Maryland (i.e. the fragment constituting most of the total peak intensity) changed on each sampling date (Fig. 4). A single phylotype (389 bp, putatively identified as Aureococcus anophagefferens) dominated at both locations on only one sampling date (17 June 2004). Only 5 of 13 dates on which samples from $\mathrm{QB}$ and SB were collected on the same day (4 km apart) exhibited the same dominant fragment size (Fig. 5); this was the case for only 4 of 12 dates for BSC and PB (20 km apart; Fig. 6). A number of the fragment sizes (e.g. $184 \mathrm{bp}$ in the PL samples) increased from undetectable levels in the T-RFLP analyses on one sampling date to briefly representing the most intense fragment on the next date, and then returning to undetectable levels within the time span of $1 \mathrm{mo}$.

A total of 24 different phylotypes (i.e. specific fragments) constituted the strongest signal in at least one of the samples, and several phylotypes dominated multiple times at a single location. For example, the fragment length $378 \mathrm{bp}$ dominated in 13 different samples and was dominant more than once in 4 of the 6 locations. Other fragments

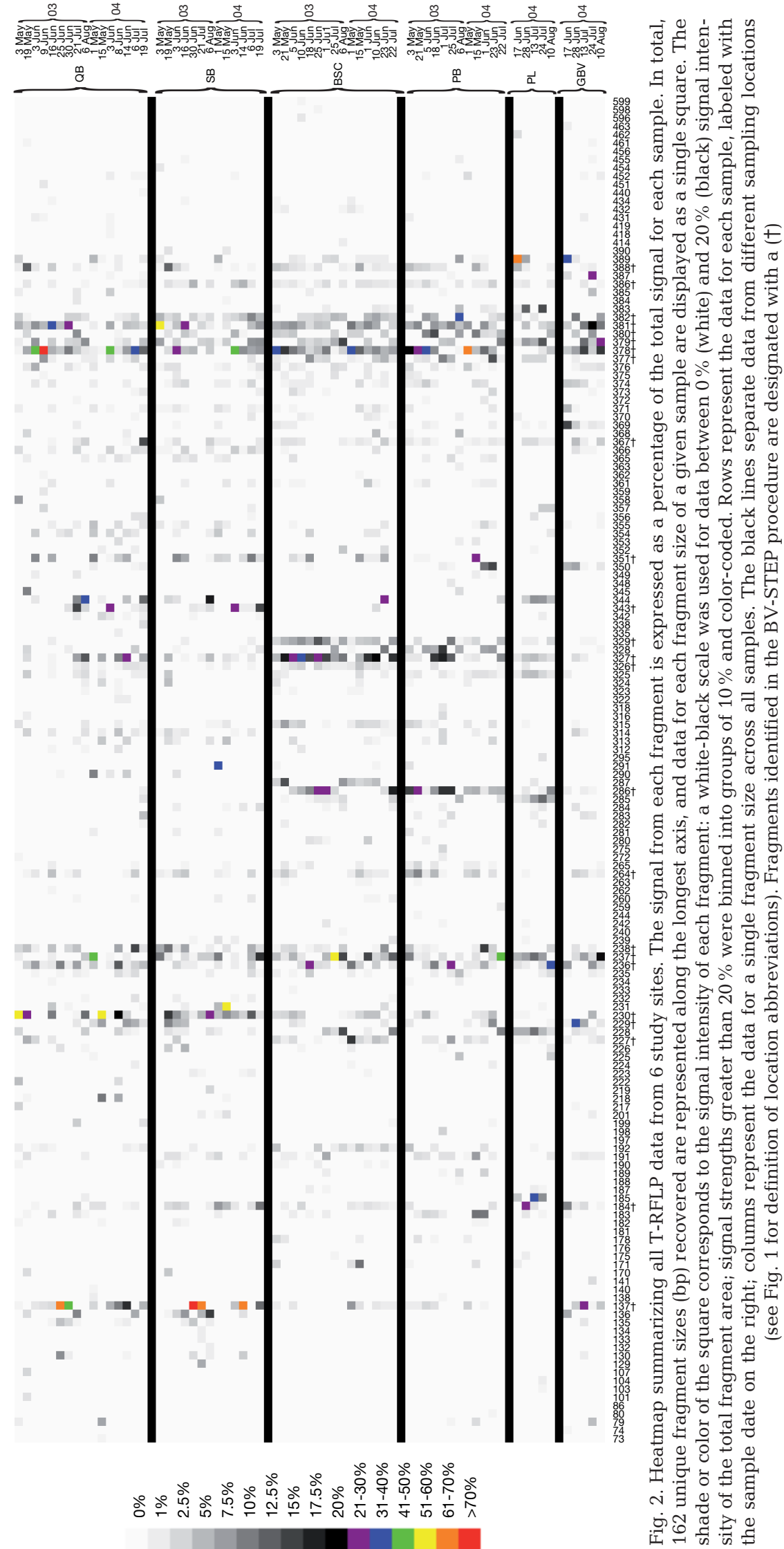



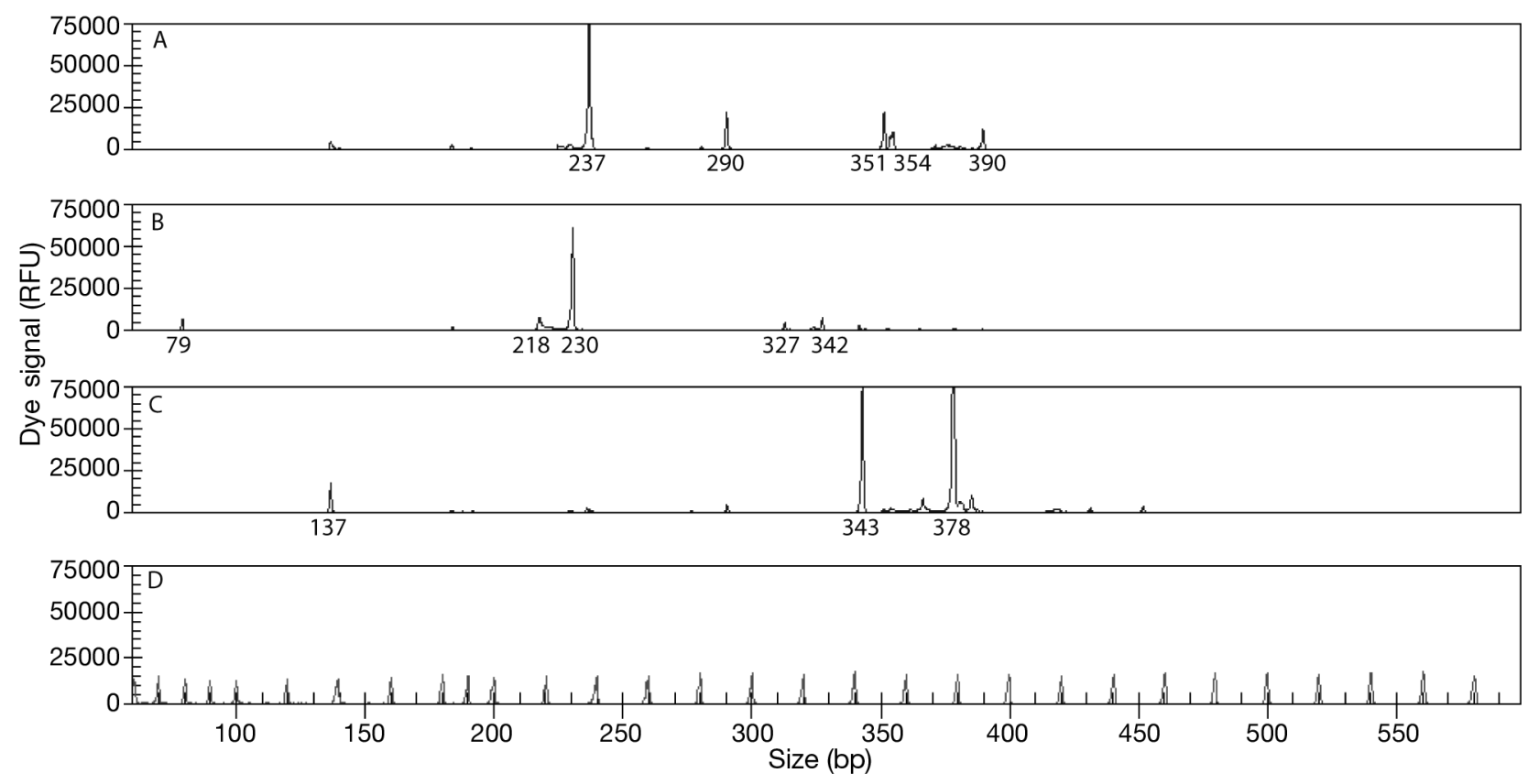

Fig. 3. Raw chromatograms of T-RFLP results obtained from 3 samples collected sequentially from Shinnecock Bay on (A) 1 May 2004, (B) 15 May 2004, (C) 3 June 2004. Fragment intensity (relative fluorescence units, RFU) is shown on the vertical axis and fragment size (bp) along the horizontal axis. The sizes of the most prominent fragments are indicated (note: not all fragments above threshold are indicated in this figure). (D) Example of the signal from the size standard
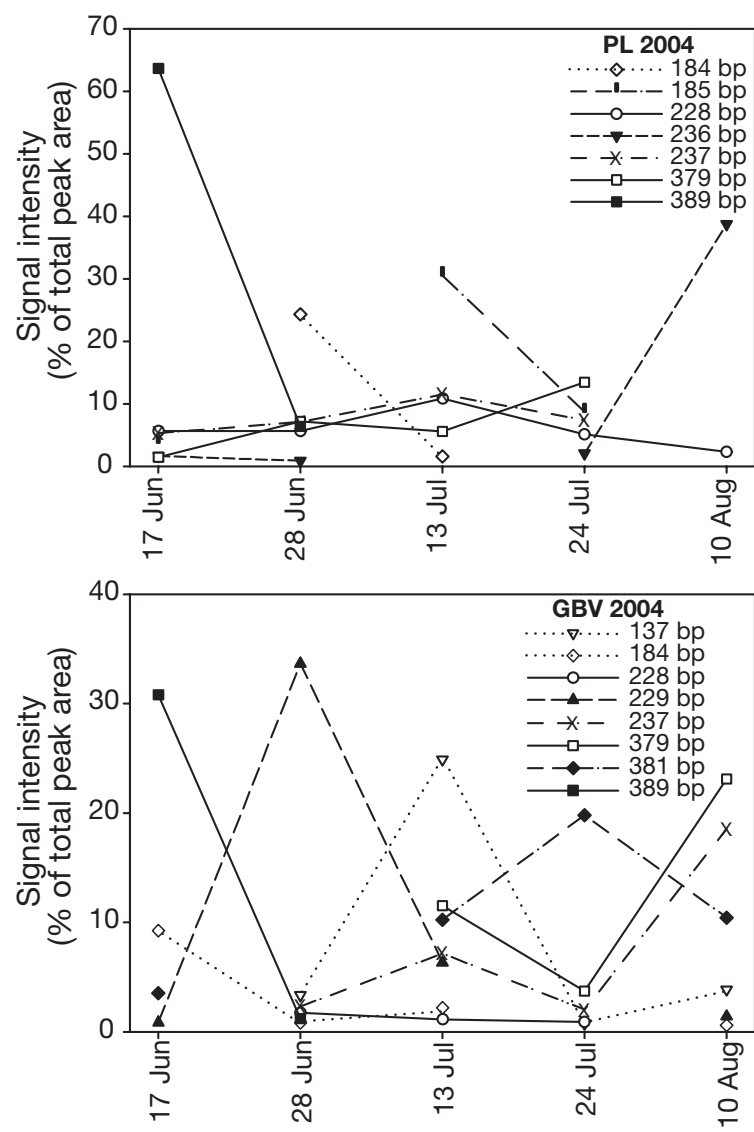

Sample date contributed $10 \%$ or more to the total T-RFLP signal in numerous samples but never dominated the T-RFLP patterns. For example, fragment size $228 \mathrm{bp}$ was present in all 6 sampling locations, but its highest relative signal strength was $14 \%$ of the total on 6 August 2003 at the BSC site.

Eight clone libraries of $18 \mathrm{~S}$ genes were established and the 5' ends of these genes sequenced in order to determine the probable taxonomic identities of specific fragments recovered in the T-RFLP analysis. A phylogenetically diverse array of protistan taxa was revealed by the sequencing effort. Clones related to diatoms, ciliates, chlorophytes and dinoflagellates dominated the clone libraries. The resulting sequences were subjected to an in silico restriction digestion in order to provide putative taxonomic identities of T-RFLP fragments based on a comparison of the fragment sizes in the in silico digestion to those obtained from the T-RFLP analysis. Out of a total of 849 partial $18 \mathrm{~S}$ sequences, 629 were of suitable size, quality, and

Fig. 4. T-RFLP data for the dominant phylotypes (specific fragment sizes) for Public Landing (PL) and Greenbriarville (GBV), Maryland, over the sampling period. Signal intensities for each fragment are expressed as a percentage of total signal intensity (vertical axis). For clarity, only fragment sizes constituting major signals are shown 

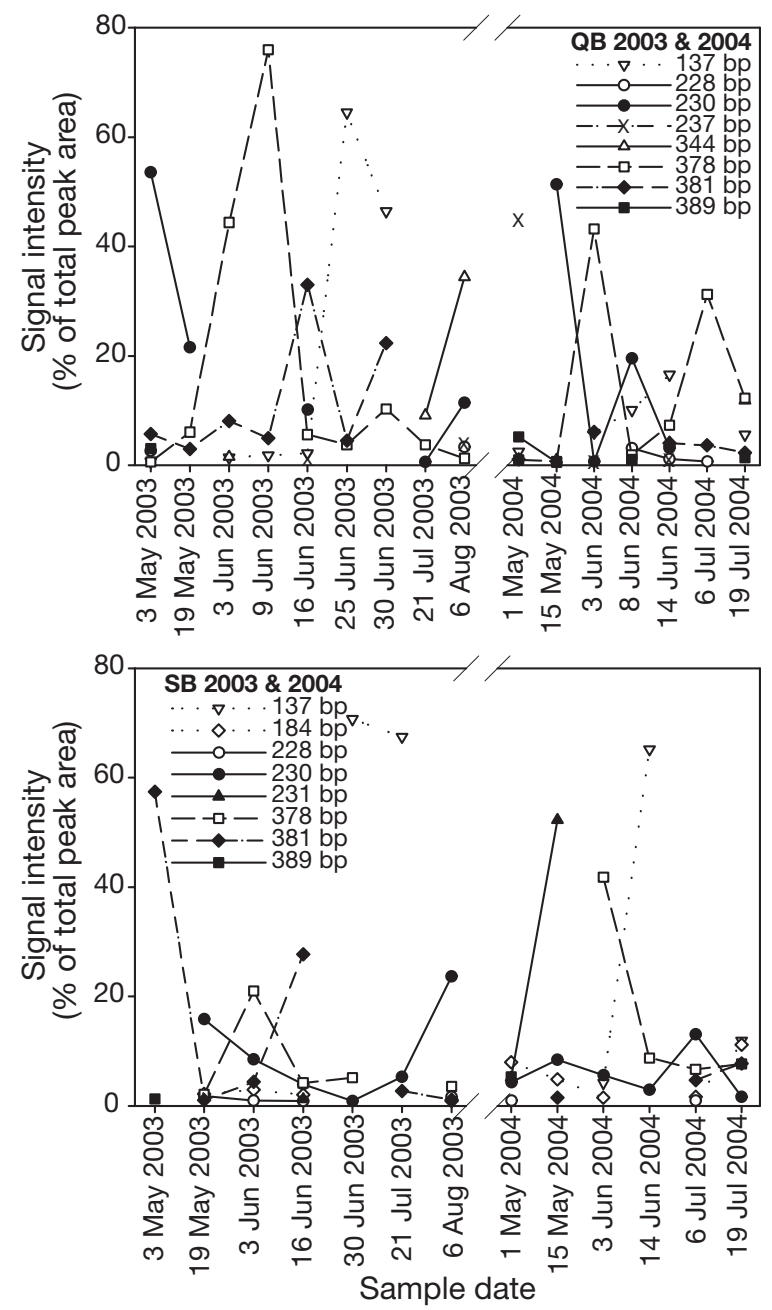

Fig. 5. T-RFLP data for the dominant phylotypes (specific fragment sizes) for Quantuck Bay (QB) and Shinnecock Bay (SB), New York. For details, see Fig. 4

vector orientation to permit a prediction of the fragment size that would be generated from that sequence in our T-RFLP assay. Sequences were submitted to NCBI using BLAST, and the sequences yielding the same organism as the first named taxon (at least to genus) were grouped together.

Of the 162 fragment sizes observed, 63 returned a putative identification as a result of this analysis (Table 2). For example, the 17 June 2004 samples from the PL and GBV sites corresponded to a brown tide caused by Aureococcus anophagefferens (Deonarine et al. 2006), and the fragment patterns for these samples revealed a dominant signal from a fragment $389 \mathrm{bp}$ in length, which is the predicted fragment size of $5 \mathrm{~A}$. anophagefferens sequences contained in the clone libraries. The signal from this fragment diminished in relative abundance within $2 \mathrm{wk}$ and a new taxon replaced the brown tide organism as the domi-
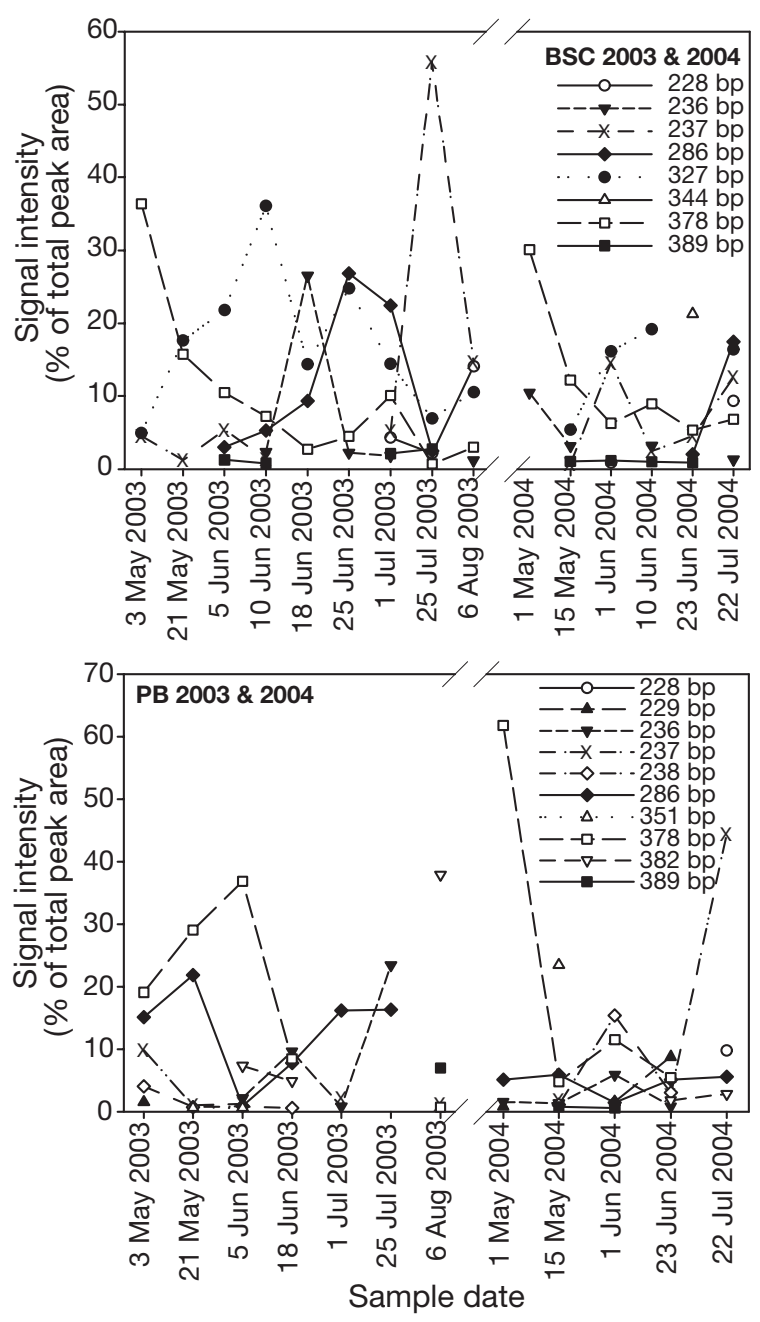

Fig. 6. T-RFLP data for the dominant phylotypes (specific fragment sizes) for Bay Shore Cove (BSC) and Patchogue Bay (PB), New York. For details, see Fig. 4

nant T-RFLP signal. Sequences of markedly different identity yielded the same theoretical fragment size in some cases. For each fragment with multiple possible identities, the sequence that yielded that fragment size and occurred most commonly in the clone libraries was chosen as the most likely identity of that fragment. Less abundant sequences were designated as alternative identifications (Table 2). Nineteen of these fragments yielded a second possible identity, 9 fragments had a third possible identity and 3 had a fourth (i.e. these sequences yielded different BLAST matches but the same fragment sizes).

Taxa that exhibited strong signals in the T-RFLP patterns often correlated well with sequences that displayed high relative abundances in the clone libraries (compare data in Figs 4 to 6 with Table 2). Fragments that represented dominant signals in the T-RFLP patterns and were also well represented in the clone 
libraries included Geminigera cryophila (cryptophyte, 184 bp), Crustomastix stigmatica (chlorophyte, 185 bp), Minutocellus sp. (diatom, 228 bp), Ostreococcus tauri (chlorophyte, 229 bp) Strombidium sp. (ciliate, 236 bp), Varistrombidium sp. (ciliate, 237 bp), Takayama cf. pulchellum (dinoflagellate, 238 bp), Nannochloris atomus (chlorophyte, 286 bp), Chaetoceros calcitrans (diatom, $344 \mathrm{bp}$ ); Rimostrombidium sp. (ciliate, $351 \mathrm{bp}$ ), Amoebophrya sp. (dinoflagellate, 378 bp) and Aureococcus anophagefferens (pelagophyte, $389 \mathrm{bp}$ ). The presence of many of these species has been substantiated by their concurrent detection using light and/or electron microscopy (Deonarine et al. 2006).

Notable exceptions to the correlation between fragment intensity in T-RFLP patterns and representation in the clone libraries existed. Several fragments that produced intense bands in the T-RFLP patterns were poorly represented or unrepresented among the theoretical fragment sizes obtained based on in silico

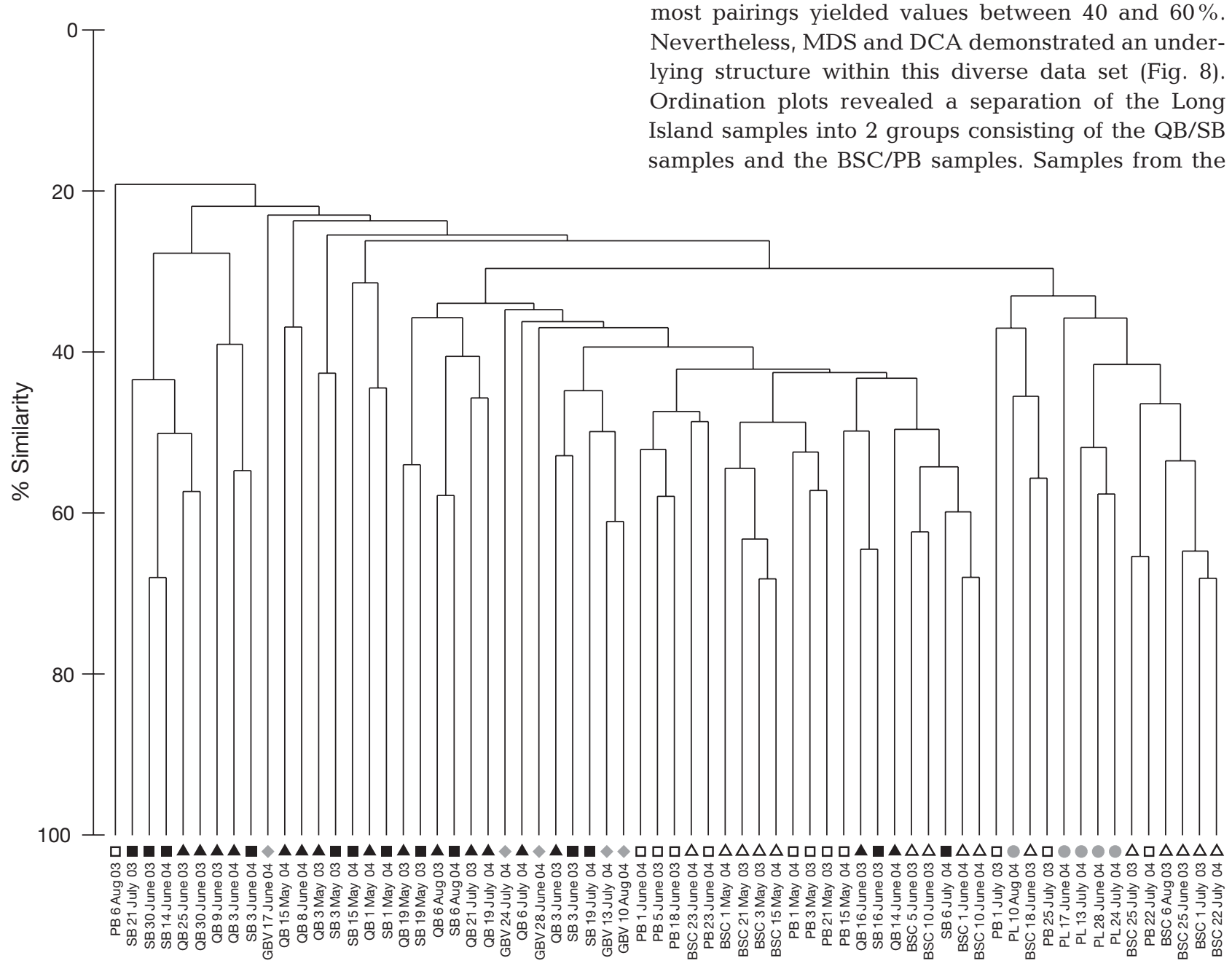

digestion of the sequenced clones (e.g. fragment sizes of 137, 327 and $381 \mathrm{bp}$ ). Many fragments could not be assigned putative taxonomic identities, presumably because of the limited number of samples that could be cloned and the limited number of sequences per library that could be sequenced in this study. Similarly, some fragment sizes were absent from the T-RFLP patterns that should have been dominant fragments based on in silico digestion of sequences commonly encountered in the clone libraries. Sequences of the ciliate Strombilidium sp. (theoretical fragment size of $290 \mathrm{bp}$ ), the chlorophyte Nannochloris maculata (328 bp) and the diatoms Chaetoceros sp. (342 bp) and Cyclotella meneghiniana (377 bp) were commonly encountered in the clone libraries but could not be correlated with specific fragments in the T-RFLP analysis.

Cluster dendrograms of T-RFLP patterns illustrated considerable differences among assemblage structure for most of the samples (Fig. 7). None of the paired samples revealed similarities greater than $70 \%$ and most pairings yielded values between 40 and $60 \%$. Nevertheless, MDS and DCA demonstrated an underlying structure within this diverse data set (Fig. 8). Ordination plots revealed a separation of the Long Island samples into 2 groups consisting of the QB/SB samples and the BSC/PB samples. Samples from the

Fig. 7. Percentage similarity among all samples. Samples collected from the same location are designated with the same symbol. See Fig. 1 for definition of location abbreviations 
GBV site were distributed at the interface of the 2 groups, while the PL samples grouped within the BSC/PB group. Both MDS and DCA conducted on untransformed and square root-transformed T-RFLP data resulted in the same general pattern. The square root-transformed plots are shown in Fig. 8. MDS plots on 3 dimensions reduced the Kruskal stress statistic to 0.19 while demonstrating the same pattern of sample grouping; however, only the 2-dimensional plot is shown in Fig. 8 due to the difficulty of displaying 3-dimensional plots.

The location-based structuring among samples observed in the ordination diagrams was confirmed by an ANOSIM test, which revealed a significant difference between the T-RFLP data by sample location (global ANOSIM test, $\mathrm{p}<0.05$ ). The T-RFLP community fingerprints of the Long Island samples were

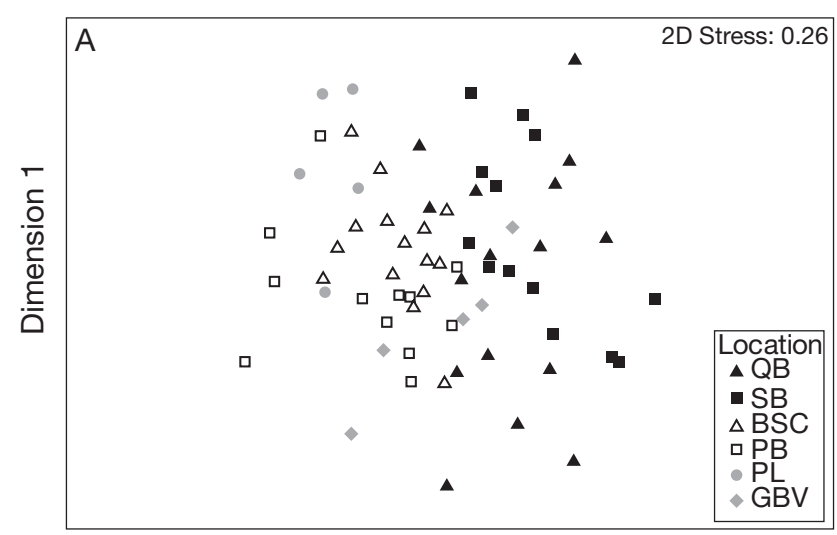

Dimension 2

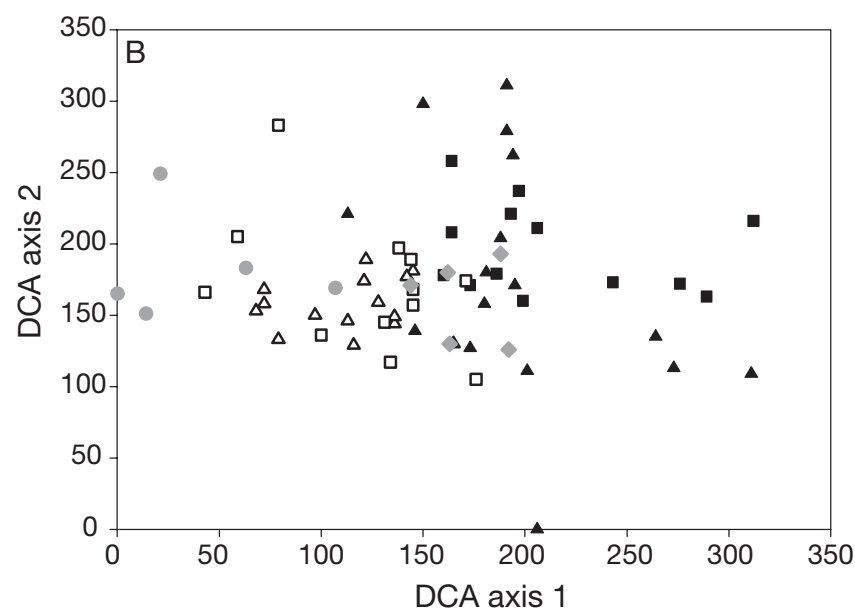

Fig. 8. Ordination diagrams derived from square roottransformed T-RFLP data. (A) Multidimensional scaling (MDS) plot constrained to 2 dimensions. (B) Detrended correspondence analysis (DCA) plot. For clarity, only the ordination of the samples is displayed for the first 2 axes derived by DCA then compared to each other. All locations were significantly different from each other, except for QB vs. SB (pairwise ANOSIM test, $\mathrm{p}=0.06$, all other $\mathrm{p}<$ 0.05). There were no significant differences among samples grouped by year ( $\mathrm{p}=0.36$ ) or between samples collected from the northern sites (Long Island) relative to the 2 southernmost stations ( $p=0.12$ ). Community structuring along seasonal lines was evident from significant differences between samples grouped as early summer (May and June combined) vs. those grouped as late summer (July and August combined) ( $p=0.009$ ). Investigation of possible correlations of the significant groupings among the community T-RFLP patterns with environmental variables using the BIO-ENV procedure revealed a weak but significant correlation for a subset of 5 variables: chl $a$, DOC, POC, salinity and temperature $(p=0.001, \rho=$ 0.306).

The BV-STEP procedure within the PRIMER software identified a subset of 24 from a total of 162 fragments that were key to driving the changes in community structure observed in the MDS plots and within the series of ANOSIM tests. This subset correlated strongly with the original similarity matrix containing the total data set $(\mathrm{R}=0.95)$. These fragments were then removed from the data set and the procedure repeated to determine whether an additional subset with a high correlation could be identified. The highest correlation from the remaining data, drawn from a combination of 45 variables, was $\mathrm{R}=0.69$.

\section{DISCUSSION}

The microbial communities studied retained high species diversity even during major bloom events, and the dominant taxa changed repeatedly, significantly and frequently (within 1 to $2 \mathrm{wk}$ ) in all environments sampled. The overall level of similarity among the microbial assemblages was low. However, samples taken 1 yr apart but at the same location and during the same season displayed the greatest similarity observed in the present study. These findings indicate a highly dynamic and resilient assemblage of microbial eukaryotes that adjusts rapidly to subtle changes in environmental conditions.

\section{T-RFLP analysis of microbial eukaryote diversity}

DNA fragment analysis has proven to be an appropriate approach for assessing shifts in the species composition of the dominant protistan taxa within natural assemblages of microbial eukaryotes (Van Hannen et al. 1998, Díez et al. 2001, Schabereiter-Gurtner et al. 
2001). Previous work comparing the results of DNA fragment analysis for assessing community structure to cloning and sequencing have demonstrated a good agreement between the 2 methods (Countway et al. 2005). DNA sequencing has proven to be more effective than fragment analysis in assessing total species richness and, in particular, the presence of rare phylotypes (Stoeck \& Epstein 2003, Romari \& Vaulot 2004, Lovejoy et al. 2006, Countway et al. 2007), while fragment analysis adequately captures information on the 'common' phylotypes (in the present study, an average of 25 fragments were observed in each T-RFLP pattern; Table 1) with significantly less analytical effort and at lower cost than large sequencing projects. The current study extends the use of T-RFLP to the investigation of microbial assemblages across multiple environments and of more samples than would have been practical using cloning and sequencing.

Computational tools for obtaining putative identities of specific DNA fragment sizes obtained by fragment analysis approaches have begun to appear (Kent et al. 2003, Marsh 2005); however, at present these tools have been employed primarily for prokaryotic organisms for which a large sequence database exists. In the present study, more than 600 eukaryotic sequences from several of the same DNA samples processed for T-RFLP were used to assign putative identifications to 63 of the 162 unique fragment sizes observed (Table 2). This analysis revealed the presence of a wide phylogenetic diversity of microbial eukaryotes, including chromalveolates (especially ciliates, dinoflagellates, diatoms, chrysophytes, pelagophytes), chlorophytes, cryptophytes, and fungi. The underlying assumptions for assigning these identities were that a fragment of a certain size represented one and only one eukaryotic taxon, and that the taxa represented in the fragment patterns were also represented in the clone libraries. As noted in 'Results', several protistan taxa yielded the same fragment size and would therefore not be uniquely distinguished by the DNA fragment analysis. In these cases, putative identifications of a specific fragment size were assigned based on the frequency of the different taxa in the clone libraries, but alternative taxonomic identifications were also reported (Table 2).

The T-RFLP methodology employed in this study has proven to be robust and reproducible (albeit proof in this study is based on only 2 samples). The 2 samples processed independently in triplicate showed an average standard deviation of 0.58 to $1.33 \%$ total peak area per fragment. Only 2 out of more than 100 fragments had sizes that differed in the triplicate patterns (and by only $1 \mathrm{bp}$ ). It should be noted, however, that the detection of minor signals in the T-RFLP pattern (fragments constituting $\leq 1 \%$ the total signal area), was variable.
This result is analogous to the variability associated with observing lowest abundance operational taxonomic units when sequencing eukaryotic environmental clone libraries (Stoeck et al. 2003, Countway et al. 2005, Lovejoy et al. 2006, Caron \& Schnetzer 2007 , Countway et al. 2007).

\section{Rapid changes in microbial eukaryote assemblages}

The most striking result from our fragment analysis was the highly dynamic nature of the composition of the microbial eukaryotic assemblage within and among the environments investigated in this study. Compositional differences in the dominant taxa were observed among the 6 sites surveyed during the study, and at temporal scales as short as $1 \mathrm{wk}$ at each site. Overall, low levels of similarity among the 66 samples were revealed by cluster analysis. Few samples (11 of 66) exhibited more than $60 \%$ overall similarity, and none of the samples were $\geq 70 \%$ similar (Fig. 7). Correlation with environmental variables as determined using the BIO-ENV procedure revealed a significant but weak relationship ( $p=0.001, \rho=0.306)$. It was not surprising that the highest correlation between environmental variables and community T-RFLP patterns in this study was weak, given the high variability observed among samples in the cluster analysis, the large number of locations and sampling times, and the presumably multiple trophic levels combined in the T-RFLP analysis.

The same microbial eukaryotic taxon remained dominant on successive sampling dates in only a small number of successive samples across all study sites (Figs. 4 to 6). In the latter case, these samples still demonstrated shifts in the subdominant taxa. In many cases, dominant taxa occurred as subdominants when they were not the most abundant taxon (e.g. 379 bp at PL; Fig. 4), while other taxa were undetectable on the sampling dates prior to or following the dates on which they dominated an assemblage (231 bp on 15 May 2004 or 378 bp on 3 June 2004 at SB; Fig. 5). The ability of DNA fragment analysis techniques to assess overall community structure at relatively fine temporal scales across numerous geographical locales has provided unique insights into the highly dynamic nature of microbial eukaryotic assemblages.

Substantive changes in the composition of the eukaryotic community on these time scales are not without precedent. Sieracki et al. (2004) noted a rapid succession of phototrophic and heterotrophic picoand nanoplankton in Quantuck Bay, Long Island during 2000. Transitions between dominant taxa occurred on time scales of 1 to $3 \mathrm{wk}$, consistent with the findings of the present study. Similarly, a significant 
but transient bloom of the minute prasinophyte Ostreococcus sp. occurred in West Neck Bay along the coast of Long Island during June of 2001 (O'Kelly et al. 2003). That bloom appeared and dissipated in less than 2 wk and attained a peak abundance of $5 \times 10^{5}$ cells $\mathrm{ml}^{-1}$.

In the present study, a fragment that was putatively identified as Ostreococcus tauri dominated the T-RFLP patterns from QB, Long Island, during early May 2003 and 2004. Moreover, other fragments putatively identified as other minute chlorophytes (e.g. species of Nannochloris and Picocystis), as well as other small algae, appeared commonly as dominants in T-RFLP patterns on various dates and at various locations. This result appears to indicate that small eukaryote algae were a persistent component of the phytoplankton communities of these ecosystems, although the particular species that dominated the assemblage was highly variable. This finding is consistent with the 'pico-algal niche' hypothesis (Sieracki et al. 2004) which was developed from the'open phytoplankton niche' hypothesis (Smayda \& Villareal 1989). This hypothesis contends that a small algal 'niche' is a common component of estuaries, but that complicated interactions of physics, chemistry and biology result in frequent and relatively unpredictable changes in the dominant taxon among the myriad of small phytoplankton species present in a community.

Previous work has documented a rapid response of natural microbial eukaryotic communities to relatively minor perturbations, such as containment of seawater in incubation bottles (Countway et al. 2005). The microbial communities assessed in our study changed rapidly, presumably in response to minor changes in environmental conditions or biological interactions, while maintaining similar levels of diversity. The succession of dominant taxa observed in the present study implies that many of the taxa that were originally present in these ecosystems at relatively low abundance were capable of attaining high abundances in a relatively short period of time.

High levels of dissimilarity for the microbial eukaryotic assemblages were also apparent at small spatial scales among the study sites examined in this study. Only 1 out of 11 sample pairs that clustered at a similarity level of $>60 \%$ were samples that were collected on the same date from adjacent geographical locations (QB and SB, 16 June 03; Fig. 7). These results indicate that both small-scale heterogeneity and small-scale temporal variability contributed to the highly dynamic nature of the composition of microbial eukaryotic assemblages.

Microbial eukaryotic assemblage composition at a particular sampling locale generally demonstrated the highest degree of similarity for samples collected during the same season but in different years (Figs. 4 to 7 ). Three of the 4 highest Bray-Curtis similarity values (ca. 68\%) obtained from the cluster analysis were observed for pairs of samples collected from the same locations on different years (SB: 30 June 03 and 14 June 04; BSC: 3 May 03 and 15 May 04; BSC: 1 July 03 and 22 July 04; Fig. 7). Specific microbial eukaryotic taxa often appeared at similar times of year during the 2 years of the study. For example, a fragment of $378 \mathrm{bp}$ dominated the assemblages during May and early June of 2003 and 2004 in all of the Long Island estuaries (Fig. 5 \& 6). Similarly, a fragment of 230 bp (putatively identified as a Ostreococcus tauri) dominated at similar seasons in both years in QB and SB (Fig. 5). The occurrence of specific taxa at certain times of the year is not surprising in itself, but the otherwise high spatial and temporal variability of the microbial eukaryotic assemblage makes these seasonal reoccurrences striking.

Overall diversity of the microbial eukaryotic assemblages, as measured by species richness and evenness, remained relative high in all environments throughout the study. The overall species richness observed in these samples was 10 to 36 dominant phylotypes in a single sample, as estimated by the total number of fragments detected in the T-RFLP patterns (Table 1). However, it is important to recognize that samples that were strongly dominated by one or a few taxa (i.e. intense signals for particular fragments) could reduce the total number of fragments that might be detectable using T-RFLP because the method is affected by the relative abundances of peak heights. Nevertheless, there was no clear trend apparent in the distribution of these values among the samples. Similar to total species richness, diversity indices calculated for the samples varied over a significant range (Shannon index: 1.04 to 3.16; Simpson index: 1.70 to 18.07 ) but there was no apparent relationship with location or timing of sample collection (Table 1).

The Shannon and Simpson indices were not dramatically affected by the presence of a brown tide at the PL or GBV sites during June 2004 (Table 1). A fragment of $389 \mathrm{bp}$ (putatively identified as Aureococcus anophagefferens; Table 2) dominated the T-RFLP patterns from these latter estuaries on 17 June 2004 (Fig. 4), and corresponded to a peak abundance of $2.5 \times 10^{6}$ and $1.2 \times 10^{6}$ cells $\mathrm{ml}^{-1}$ of $A$. anophagefferens (PL and GBV respectively) (Deonarine et al. 2006). The samples collected from those ecosystems at that time yielded diversity values that were not the lowest values observed in the study (61st in PL and 46th in GBV out of 66 samples). It is presently unknown how the estimation of species diversity using these indices might be affected by molecular analyses that require amplification of DNA by PCR. Moreover, we note that 
the bloom in CB had begun in May and declined by an order of magnitude during the $10 \mathrm{~d}$ after our 17 June sampling, suggesting that the event was nearing its end. Nevertheless, our results indicate that these assemblages may recover rapidly from perturbations caused by brown tides.

\section{Forces shaping community structure}

A more comprehensive understanding of the community dynamics and the influence of environmental factors in shaping these communities was gained through the use of MDS and DCA to visually summarize the variation in the dataset. Clustering assumes that discrete groupings of similar samples exist within the data, while ordination methods attempt to visualize the relationship between the samples when considering multiple variables simultaneously and with no prior assumption that discrete groups are present (McGarigal et al. 2000). The results of the 2 ordination methods were remarkably similar with 2 broad groups observed. These groups were separated largely according to their sampling location, with $\mathrm{QB}$ and $\mathrm{SB}$ from Long Island forming one group while $\mathrm{BSC}, \mathrm{PB}$, GBV and PL formed the other (Fig. 8). This finding is noteworthy given that the 2 methods operate on different mathematical principles (Kenkel \& Orloci 1986, Minchin 1987, Wartenberg et al. 1987, Peet et al. 1988).

The ANOSIM tests confirmed the general groupings of samples in the ordination plots and further indicated significant grouping of the data according to the 6 sampling locations. The global test value was significant $(p<0.05)$, indicating some degree of structuring according to sample location, and each pair-wise comparison of sites was significantly different from the other, except for a marginally non-significant value for the QB/SB pair $(p=0.06)$. The interpretation of these results was clearer when combined with the ordination diagrams, which visually indicated that, in addition to the grouping of samples by single locations, 2 larger groups containing samples from multiple sites were also present. The ANOSIM results also confirmed the presence of seasonal shifts in the microbial community composition, resulting in a separation of May and June from July and August samples.

The use of DNA fragment analysis to investigate changes in the dominant microbial eukaryotes in estuarine ecosystems revealed extremely high smallscale spatial and temporal heterogeneity within this component of the microbial community. Comparison of T-RFLP patterns from 6 estuaries over a $2 \mathrm{yr}$ period revealed major changes among the dominant taxa that took place unexpectedly rapidly and at smaller spatial scales than anticipated. These findings were facilitated by the application of molecular approaches and methodologies that have greatly increased our knowledge of microbial eukaryote diversity and distribution (Díez et al. 2001, Casamayor et al. 2002, Massana \& Jürgens 2003, Countway et al. 2005). The results of the present study imply that very subtle changes in environmental conditions or foodweb structure may be sufficient to result in dramatic changes in the dominant microbial eukaryotic taxa within these estuaries. While we still lack a clear understanding of the interplay of forcing factors (e.g. macro- and micronutrients, physical parameters, trophic interactions) resulting in these changes, our observations add to the understanding of the rate at which eukaryote microbial community composition can change.

Acknowledgements. The authors gratefully acknowledge the technical assistance of A. Schnetzer and A. Boulos. The authors also thank S. Deonarine for her efforts in sample collection and analysis. This study was supported by the Ecology of Harmful Algal Blooms program of the National Oceanic and Atmospheric Administration grants NA160P2790 (to C.J.G. and D.J.L.) and NA16OP2792 (to D.A.C.).

\section{LITERATURE CITED}

Altschul SF, Madden TL, Schaffer AA, Zhang J, Zhang Z, Miller W, Lipman DJ (1997) Gapped BLAST and PSIBLAST: a new generation of protein database search programs. Nucleic Acids Res 25:3389-3402

Baldwin AJ, Moss JA, Pakulski HD, Catala P, Joux F, Jeffrey WH (2005) Microbial diversity in a Pacific Ocean transect from the Arctic to Antarctic circle. Aquat Microb Ecol 41: 91-102

Berney C, Fahrni J, Pawlowski J (2004) How many novel eukaryotic 'kingdoms'? Pitfalls and limitations of environmental DNA surveys. BMC Biol 4:2-13

Bricelj WM, Lonsdale DJ (1997) Aureococcus anophagefferens: causes and ecological consequences of brown tides in US Mid-Atlantic coastal waters. Limnol Oceanogr 42: 1023-1038

Brower JE, Zar JH, von Ende CN (1998) Field and laboratory methods for general ecology. WCB/McGraw Hill, Boston, MA

> Buskey EJ, Hyatt CJ (1995) Effects of the Texas (USA) 'brown tide' alga on planktonic grazers. Mar Ecol Prog Ser 126: 285-292

Caron DA, Schnetzer A (2007) Protistan community structure. In: Hurst CJ, Crawford RL, Garland JL, Lipson DA, Mills $\mathrm{AL}$, Stetzenbach LD (eds) Manual of environmental microbiology. ASM Press, Washington, DC, p 454-468

Caron DA, Countway PD, Brown MV (2004) The growing contributions of molecular biology and immunology to protistan ecology: molecular signatures as ecological tools. J Eukaryot Microbiol 51:38-48

> Casamayor EO, Massana R, Benlloch S, Øvreås L and others (2002) Changes in archaeal, bacterial and eukaryal assemblages along a salinity gradient by comparison of genetic fingerprinting methods in a multipond solar saltern. Environ Microbiol 4:338-348

> Cerrato RM, Caron DA, Lonsdale DJ, Rose JM, Schaffner RA (2004) Effect of the northern quahog Mercenaria merce- 
naria on the development of blooms of the brown tide alga Aureococcus anophagefferens. Mar Ecol Prog Ser 281: 93-108

> Countway PD, Gast RJ, Savai P, Caron DA (2005) Protistan diversity estimates based on 18S rDNA from seawater incubations in the western North Atlantic. J Eukaryot Microbiol 52:95-106

Countway PD, Gast RJ, Dennett MR, Savai P, Rose JM, Caron DA (2007) Distinct protistan assemblages characterize the euphotic zone and deep sea $(2500 \mathrm{~m})$ of the western $\mathrm{N}$. Atlantic (Sargasso Sea and Gulf Stream). Environ Microbiol 9:1219-1232

> Deonarine SN, Gobler CJ, Lonsdale DJ, Caron DA (2006) Role of zooplankton in the onset and demise of harmful brown tide blooms (Aureococcus anophagefferens) in US mid-Atlantic estuaries. Aquat Microb Ecol 44: 181-195

Díez B, Pedrós-Alió C, Marsh TL, Massana R (2001) Application of denaturing gradient gel electrophoresis (DGGE) to study the diversity of marine picoeukaryotic assemblages and comparison of DGGE with other molecular techniques. Appl Environ Microbiol 67:2942-2951

Díez B, Massana R, Estrada M, Pedrós-Alió C (2004) Distribution of eukaryotic picoplankton assemblages across hydrographic fronts in the Southern Ocean, studied by denaturing gradient gel electrophoresis. Limnol Oceanogr 49:1022-1034

Egert M, Friedrich MW (2003) Formation of pseudo-terminal restriction fragments, a PCR-related bias affecting terminal restriction fragment length polymorphism analysis of microbial community structure. Appl Environ Microbiol 69:2555-2562

Gast RJ, Dennett MR, Caron DA (2004) Characterization of protistan assemblages in the Ross Sea, Antarctica by denaturing gradient gel electrophoresis. Appl Environ Microbiol 70:2028-2037

> Gastrich MD, Lathrop R, Haag S, Weinstein MP, Danko M, Caron DA, Schaffner R (2004) Assessment of brown tide blooms, caused by Aureococcus anophagefferens, and contributing factors in New Jersey coastal bays: 20002002. Harmful Algae 3:305-320

Gobler CJ, Sañudo-Wilhelmy SA (2001) Temporal variability of groundwater seepage and brown tide blooms in a Long Island embayment. Mar Ecol Prog Ser 217:299-309

Gobler CJ, Lonsdale DJ, Boyer GL (2005) A review of the causes, effects, and potential management of harmful brown tide blooms caused by Aureococcus anophagefferens (Hargraves et Sieburth). Estuaries 28:726-749

Kaplan CW, Kitts CL (2004) Bacterial succession in a petroleum land treatment unit. Appl Environ Microbiol 70: $1777-1786$

Kenkel NC, Orloci L (1986) Applying metric and nonmetric multidimensional scaling to ecological studies: some new results. Ecology 67:919-928

Kent AD, Smith DJ, Benson BJ, Triplett EW (2003) Web-based phylogenetic assignment tool for the analysis of terminal restriction fragment length polymorphism profiles of microbial communities. Appl Environ Microbiol 69: 6768-6776

King JY, Ferrara R, Tabibiazar R, Spin JM and others (2005) Pathway analysis of coronary atherosclerosis. Physiol Genomics 23:103-118

Lonsdale DJ, Cosper EM, Kim WS, Doall M, Divadeenam A, Jonasdottir SH (1996) Food web interactions in the plankton of Long island bays, with preliminary observations on brown tide effects. Mar Ecol Prog Ser 134: $247-263$
Lovejoy C, Massana R, Pedrós-Alió C (2006) Diversity and distribution of marine microbial eukaryotes in the Arctic Ocean and adjacent seas. Appl Environ Microbiol 72: 3085-3095

Marsh TL (2005) Culture-independent microbial community analysis with terminal restrictions fragment length polymorphism. Methods Enzymol 397:308-329

Massana R, Jürgens K (2003) Composition and population dynamics of planktonic bacteria and bacterivorous flagellates in seawater chemostat cultures. Aquat Microb Ecol 32:11-22

McGarigal K, Cushman S, Stafford S (2000) Multivariate statistics for wildlife and ecology research. Springer, New York

Minchin PR (1987) An evaluation of the relative robustness of techniques for ecological ordination. Vegetatio 69:89-107

O'Kelly CJ, Sieracki ME, Thier EC, Hobson I (2003) A transient bloom of Ostreococcus (Chlorophyta, Parsinophyceae) in West Neck Bay, Long Island, N.Y. J Phycol 39:850-854

> Oksanen J, Minchin PR (1997) Instability of ordination results under changes in input data order: explanations and remedies. J Veg Sci 8:447-454

Peet RK, Knox RG, Case JS, Allen RB (1988) Putting things in order: the advantages of detrended correspondence Analysis. Am Nat 131:924-934

Romari K, Vaulot D (2004) Composition and temporal variability of picoeukaryote communities at a coastal site of the English Channel from 18S rDNA sequences. Limnol Oceanogr 49:784-798

Saari TA, Saari SK, Campbell CD, Alexander IJ, Anderson IC (2007) FragMatch: a program for the analysis of DNA fragment data. Mycorrhiza 17:133-136

Schabereiter-Gurtner C, Pinar G, Lubitz W, Rolleke S (2001) Analysis of fungal communities on historical church window glass by denaturing gradient gel electrophoresis and phylogenetic 18S DNA sequence analysis. J Microbiol Methods 47:345-354

Sieracki ME, Gobler CJ, Cucci TL, Thier EC, Gilg IC, Keller MD (2004) Pico- and nanoplankton dynamics during bloom initiation of Aureococcus in a Long Island, NY bay. Harmful Algae 3:459-470

Smayda TJ, Villareal TA (1989) The 1985 'brown-tide' and the open phytoplankton niche in Narragansett Bay during summer. In: Cosper EM, Bricelj VM, Carpenter EJ (eds) Novel phytoplankton blooms: causes and impacts of recurrent brown tides and other unusual blooms. Springer-Verlag, New York, p 159-187

Sogin ML, Morrison HG, Huber JA, Welch DM and others (2006) Microbial diversity in the deep sea and the underexplored 'rare biosphere'. Proc Natl Acad Sci USA 103: 12115-12120

Stoeck T, Epstein S (2003) Novel eukaryotic lineages inferred from small-subunit rRNA analyses of oxygen-depleted marine environments. Appl Environ Microbiol 69: $2657-2663$

> Stoeck T, Taylor GT, Epstein SS (2003) Novel eukaryotes from the permanently anoxic Cariaco Basin (Caribbean Sea). Appl Environ Microbiol 69:5656-5663

Tracey GA (1988) Feeding reduction, reproductive failure, and mortality in Mytilus edulis during the 1985 'brown tide' in Narragansett Bay, Rhode Island. Mar Ecol Prog Ser 50:73-81

> Van Hannen EJ, Van Agterveld MP, Gons HJ, Laanbroek HJ (1998) Revealing genetic diversity of eukaryotic microorganisms in aquatic ecosystems by denaturing gradient gel electrophoresis. J Phycol 34:206-213 
Wartenberg D, Ferson S, Rohlf FJ (1987) Putting things in order: a critique of detrended correspondence analysis. Am Nat 129:434-448

> Wazniak CE, Glibert PM (2004) Potential impacts of brown tide, Aureococcus anophagefferens, on juvenile hard

Editorial responsibility: Daniel Vaulot,

Roscoff, France clams, Mercenaria mercenaria, in the coastal bays of Maryland, USA. Harmful Algae 3:321-329

Zeidner G, Béjà O (2004) The use of DGGE analyses to explore eastern Mediterranean and Red Sea marine picophytoplankton assemblages. Environ Microbiol 6:528-534

Submitted: January 1, 2008; Accepted: September 24, 2008

Proofs received from author(s): January 19, 2009 